\title{
The functional decline of hospitalised older patients - are we doing enough?
}

\author{
R. McCullagh ${ }^{\mathrm{a}, *}$, E. Fitzgerald ${ }^{\mathrm{b}}$, K. O'Connor ${ }^{\mathrm{c}}$, L. Broderick $^{\mathrm{d}}$, C. Kennedy ${ }^{\mathrm{a}}$, N. O’Reilly ${ }^{\mathrm{a}}$, \\ R. Martin ${ }^{\mathrm{c}}$ and S. Timmons ${ }^{\mathrm{e}}$ \\ ${ }^{a}$ Physiotherapy Department, Mercy University Hospital, Cork, Ireland \\ ${ }^{\mathrm{b}}$ Royal College of Surgeons, Dublin, Ireland \\ ${ }^{\mathrm{c}}$ Department of Geriatric Medicine, Mercy University Hospital, Cork, Ireland \\ ${ }^{\mathrm{d}}$ Physiotherapy Department, St Patrick's Hospital, Cork, Ireland \\ ${ }^{\mathrm{e}}$ Centre for Gerontology \& Rehabilitation, School of Medicine, University College Cork, Cork, Ireland
}

A recently published paper found that higher levels of physical activity (PA) and fitness were associated with better Health Related Quality of Life (HRQOL) in older people recently discharged from hospital [1]. The authors recommend, "physical activity... while in hospital... may be important in order to encourage patients to actively preserve independence and HRQOL", specifically "targeting those with lower levels of physical activity ... . and multiple comorbidities". Studies have shown small positive benefits from additional exercise for older medical patients [2-4] and further meta-analysis suggested that targeting the frailer might strengthen the effects seen [5].

We conducted a small study in 2011 to measure the effects of an augmented prescribed exercise program (APEP) for frail medical acute in-patients [6]. We recruited 40 frail patients who were aged $\geq 65$ years, had an anticipated LOS $>3$ days, due for discharge home and needed a walking aid on admission. We allocated them to a usual care group (control) consisting of three physiotherapy sessions weekly or the APEP group consisting of usual care augmented with two assisted exercise-sessions daily, Monday-Friday. The research physiotherapist delivered the exercise

\footnotetext{
${ }^{*}$ Corresponding author: Ruth McCullagh, Physiotherapy Department, Mercy University Hospital, Cork, Ireland. Tel.: +353 21 4935340; E-mail: r.mccullagh@ucc.ie.
}

prescription which included strengthening, balance and endurance exercises.

We analysed a complete data set for 17 of the control group and 15 of the APEP group using the Mann-Whitney U non-parametric Test (Matlab ${ }^{\circledR}$ R2011B). We found a median length of stay (LOS) of 10 days (IQR, 8-12 days) for the APEP group compared to a median LOS of 12 days (IQR, 9-15 days) for the control group ( $p=0.17$, intention-totreat analysis, $p=0.21$ ). At discharge, the APEP group showed better physical performance (Short Physical Performance Battery, $p=0.03$ ) and HRQOL (EQ-5D Activity, $p=0.02$, Visual Analogue Scale, $p=0.001$ ). Exercise adherence was over $68 \%$ (SD, 26.5\%) in the APEP group. We now plan to study a larger cohort of 220 patients as part of a funded RCT.

This intervention is not complex, easy to deliver in the busy clinical setting, and could potentially transform services for the frail patient.

We can still do better. Motivating patients to remain active in hospital, especially independently, is challenging. It requires a change in approach from the interdisciplinary team rather than additional resources. As part of the study, we conducted semi-structured interviews with all the participants, [7] which revealed that the hospital environment encourages inactivity, and that patients waited for instruction to exercise, 
especially from their doctor. They admitted that they needed motivation to participate in the APEP but found it beneficial, especially when the exercises were targeted to the patients' self-selected goals. These findings are similar to previous work [8, 9] and Brown et al. recently found that hospital patients' physical performance improved if they are simply supported in selecting and reaching their own mobility goals [10].

In the upcoming RCT, we plan to incorporate patient-selected goals in a twice-daily exercise program and support independent physical activity. We hope that the addition of this simple intervention will help shorten the hospital stay, and preserve independence and quality of life for the frail older adult.

\section{Acknowledgments}

The study was funded by the HRB Summer Student Scholarship Bursary 2011 (Ref No SS/2011/115). We would like to thank Dr Frances Horgan for her advice and the physiotherapy and ward staff for their assistance in this project.

\section{References}

[1] Brovold T, Skelton DA, Bergland A. Association Between Health-Related Quality of Life, Physical Fitness and Physical Activity in Older People Recently Discharged from Hospital. J Aging Phys Act 2013, Aug 27 [epub ahead of print] PMID: 23981441.
[2] Siebens H, Aronow H, Edwards D, Ghasemi Z. A randomized controlled trial of exercise to improve outcomes of acute hospitalization in older adults. J Am Geriatr Soc 2000;48: 1545-52.

[3] Jones CT, Lowe AJ, MacGregor L, Brand CA, Tweddle N, Russell DM. A randomised controlled trial of an exercise intervention to reduce functional decline and health service utilisation in the hospitalised elderly. Australas J Ageing 2006;25:126-33.

[4] de Morton NA, Keating JL, Berlowitz DJ, Jackson B, Lim WK. Additional exercise does not change hospital or patient outcomes in older medical patients: A controlled clinical trial. Aust J Physiother 2007;53:105-11.

[5] De Morton NA, Jones CT, Keating JL, Berlowitz DJ, MacGregor L, Lim WK, Jackson B, Brand CA. The effect of exercise on outcomes for hospitalised older acute medical patients: An individual patient data meta-analysis. Age Ageing 2007;36:219-22.

[6] McCullagh R, Fitzgerald E, Martin R, Kennedy C, O'Reilly N, O'Connor K, Timmons S. An augmented exercise programme in the acute setting can improve mobility and quality of life in frail hospitalised older patients: A pilot trial. J Aging Phys Act 2012;20:S218-9.

[7] Broderick L, Savage E, McCullagh R, Bantry-White E, Timmons S. Influences on Exercise Behaviours of Frail Older Adults in the Acute Setting. Ir J Med Sci 2013;182: S179-296

[8] Brown CJ, Redden DT, Flood KL, Allman RM. The under recognized epidemic of low mobility during hospitalization of older adults. J Am Geriatr Soc 2009;57:1660-5.

[9] Kuys SS, Dolecka UE, Guard A. Activity level of hospital medical inpatients: An observational study. Arch Gerontol Geriatr 2012;55:417-21.

[10] Mirkin M. Walking study shows 'it's feasible and safe to get patients out of bed' [Internet] 2013. [cited 2013, December 16]. Available from http://www.research.va.gov/ resources/pubs/docs/researchcurrents_summer2013.pdf 